\title{
ESTIMATIVA DE FATORES DE DETERIORAÇÃO A PARTIR DOS RESULTADOS DE PROGRAMAS DE INSPEÇÃ̃ E MANUTENÇÃO
}

\author{
Fábio Cardinale Branco ${ }^{1}$, Gabriel Murgel Branco ${ }^{1}$, Alfred Szwarc ${ }^{2}$ \\ ${ }^{1}$ EnvironMentality Tecnologia com Conceitos Ambientais Ltda \\ ${ }^{2}$ ADS Engenharia e Consultoria
}

E-mails: fabio.tcl@uol.com.br, gabriel.tcl@uol.com.br, alfred.ads@ terra.com.br

\section{RESUMO}

Apesar de se basear em ensaios simples, os Programas de Inspeção e Manutenção de Veículos em Uso são uma ferramenta poderosa de avaliação de veículos em larga escala, visto que o grande volume de informações geradas faz com que seus resultados expressem tendências estatísticas representativas da evolução das emissões da frota de veículos nas condições reais de uso, levando em conta a qualidade e tipo de combustíveis utilizados e os hábitos de manutenção.

As estatísticas levantadas na cidade de São Paulo permitiram identificar, tanto para veículos bem mantidos como para os reprovados na inspeção, taxas de degradação das emissões com a idade e o padrão tecnológico dos veículos que, associados aos fatores de emissão certificados para veículos novos, permitiram estimar fatores de emissão mais realistas, necessários para o aprimoramento do inventário de emissões de fontes móveis.

Complementando as análises dos resultados dos poluentes medidos, monóxido de carbono e hidrocarbonetos para veículos com motor do ciclo Otto e particulados para os Diesel, os fatores de deterioração obtidos podem ser utilizados para o levantamento dos fatores para os demais poluentes apresentados no Compilation of Air Emissions Factors, da agência ambiental norte-americana EPA. Quando estiverem disponíveis dados de sensoriamento remoto ou de programas avançados de I/M, a metodologia aqui desenvolvida permitirá a obtenção de fatores de deterioração locais, para todos os tipos de veículos, dos quatro principais poluentes (monóxido de carbono, hidrocarbonetos não queimados, óxidos de nitrogênio e material particulado).

\section{INTRODUÇÃO}

Tradicionalmente os inventários de emissões oficiais brasileiros têm utilizado como fatores de deterioração os resultantes dos ensaios de durabilidade de 80 mil quilômetros, segundo a norma ABNT NBR 14008, que verifica a conformidade do projeto do veículo quanto à durabilidade dos sistemas de controle de emissão, respeitadas as recomendações de manutenção preventiva do fabricante. Entretanto, este ensaio é feito com poucos veículos, em condições extremamente bem controladas, e visa a medição precisa da capacidade do projeto em manter suas características de baixa emissão durante boa parte da vida útil do veículo, especialmente quando é mais intensamente utilizado, se a manutenção for adequada. Os 
fatores obtidos neste ensaio são numericamente pouco significativos em termos de frota em uso real, visto que a forma de dirigir e a manutenção durante o acúmulo de quilometragem são mais favoráveis e pouco representativas da realidade dos veículos em uso, mantidos por usuários comuns. Por isso, os fatores de deterioração de emissões assim obtidos têm utilidade limitada para estimativas da emissão real, restando válidos apenas como parâmetro de avaliação do projeto original do veículo ou como medida da degradação mínima que o veículo deverá sofrer se for utilizado e mantido de forma ideal, o que não ocorre na prática.

A forma adequada para estabelecer o fator médio de deterioração de um dado tipo de veículo em função da sua idade e utilização é a análise estatística das emissões medidas em um número suficientemente grande de veículos em uso para ser representativo e considerar as variações de comportamento dos usuários e o efeito de outras variáveis, como a qualidade e o tipo dos combustíveis utilizados. Também, é recomendável que essa análise trate, separadamente, veículos em condições adequadas de manutenção e veículos com manutenção deficiente, de modo a identificar o efeito e a relevância da correta manutenção neste processo. Entretanto, se tal levantamento fosse realizado em dinamômetro, demandaria uma enorme quantidade de ensaios de emissão, praticamente impossível de ser realizado no Brasil pela necessidade de um grande número desses equipamentos e alto custo desse trabalho ${ }^{1}$.

Os resultados verificados no Programa de Inspeção e Manutenção de Veículos em Uso do Município de São Paulo (I/M-SP), indicam que o mesmo foi altamente positivo na indução da manutenção preventiva e, particularmente, na manutenção corretiva, que foi registrada em proporções de $10 \%$ a $50 \%$ dos veículos inspecionados, dependendo do tipo e idade dos mesmos, produzindo variações significativas nas médias das concentrações medidas. A figura 1 apresenta dois exemplos dos mais abrangentes para as emissões de fumaça (opacidade) e de monóxido de carbono (CO), ambas em concentração do poluente nos gases de escapamento. É notória a redução de emissão atingida em veículos em todas as idades e fases do PROCONVE. No caso da opacidade, ficou evidente a capacidade de fazer com que o veículo reprovado atingisse níveis de emissão compatíveis com os veículos aprovados inicialmente, fato que se confirma para todos os tipos de veículos e poluentes.

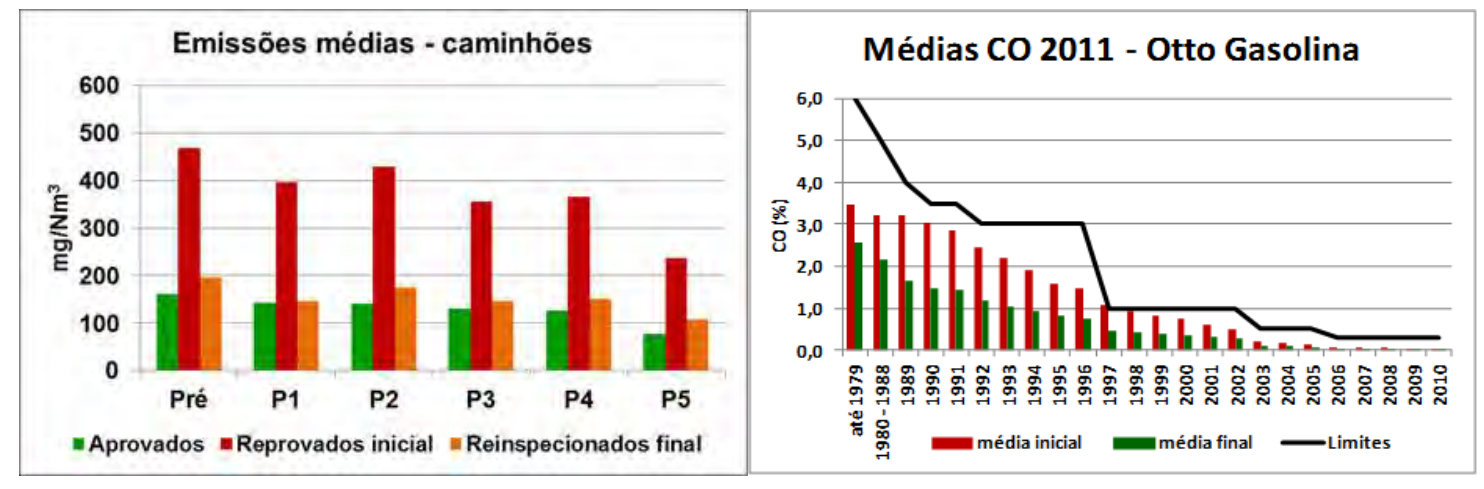

Figura 1 - Médias de concentração nos gases de escapamento

Em trabalho anterior ${ }^{2}$, foi demonstrado que as médias obtidas no Programa I/M-SP refletem uma proporcionalidade entre as emissões de um dado modelo em função do seu estado de manutenção. Em tese, esta proporcionalidade constitui um excelente indicador do índice de degradação das emissões, principalmente nos defeitos graves que permanecem presentes em todas as situações de uso (ausência de catalisador, inoperância de bicos injetores etc.), embora sejam determinados em condições mais propícias para evidenciar os defeitos do motor. Entretanto, tais índices de degradação são importantes para as estimativas realistas da emissão 
da frota circulante, em contraposição aos Fatores de Degradação AMA que são determinados nas condições mais favoráveis possíveis de manutenção, condução e utilização dos veículos.

A partir das médias das emissões anuais de material particulado (MP), hidrocarbonetos (HC) e CO, estimadas para as inspeções inicial e final, por categoria e ano de fabricação, este trabalho apresenta uma análise que permite determinar "Fatores de Deterioração em Uso Real" utilizando o mesmo conceito de proporcionalidade, isto é, aplicando-se as taxas de crescimento encontradas no I/M-SP aos Fatores de Emissão certificados de cada ano-modelo. Tais fatores foram estimados para o conjunto de veículos bem mantidos e separadamente para os altamente degradados (reprovados na inspeção).

Como base para o presente estudo foram tomados apenas os dados levantados no exercício de 2012 do Programa I/M-SP, no qual foram avaliados 3,1 milhões de veículos mediante 3,7 milhões de inspeções, sendo realizadas 198.567 inspeções em 126.816 veículos Diesel, 3.209.741 inspeções realizadas em 2.630.236 veículos leves ciclo Otto e 336.609 inspeções realizadas em 262.648 motociclos e similares, cujos resultados estatísticos garantem representatividade na quantidade de veículos por categoria, combustível e ano-fabricação e conferem robustez às conclusões obtidas neste trabalho.

Este trabalho apresenta a metodologia desenvolvida para o cálculo dos fatores de emissão de CO e HC de veículos do ciclo Otto (automóveis, seus derivados, utilitários e motociclos) e de MP de veículos e motores Diesel para cada tipo, tanto para veículos com manutenção normal quanto deficiente.

\section{Metodologia adotada}

A estimativa dos fatores de emissão dos veículos aqui apresentada baseia-se nos seguintes aspectos:

- caracterização das estatísticas dos veículos em bom estado e dos mal mantidos;

- avaliação da representatividade dos dados obtidos nos ensaios realizados de inspeção;

- determinação das concentrações médias de poluentes nos gases de escapamento, considerando dois grupos: veículos em bom estado e veículos mal mantidos;

- ajuste dos fatores de emissão obtidos em função das tendências das concentrações medidas na inspeção, limitados à quantidade disponível de carbono para a formação de $\mathrm{CO}$ e $\mathrm{CO}_{2}$, dentro de limites aceitáveis do consumo de combustível (balanço de carbono considerando as concentrações medidas desses poluentes).

Finalmente, foram selecionados fatores de deterioração norte-americanos, segundo a semelhança de padrões tecnológicos com os veículos brasileiros para comparação com os obtidos neste trabalho.

\subsection{Caracterização das estatísticas dos veículos bem e mal mantidos}

As emissões de veículos com manutenção adequada apresentam uma distribuição estatística de valores característica da sua tecnologia, variações de produção, de desgaste e de outras particularidades de utilização que os diferenciam da distribuição estatística dos mantidos inadequadamente, como ilustra a figura 2. Muitas vezes estas distribuições se superpõem, dificultando a sua identificação. 


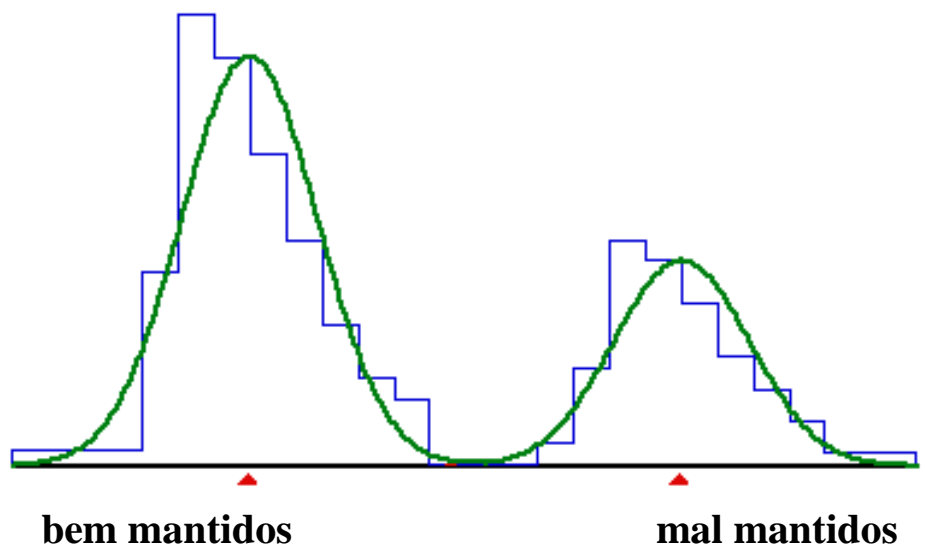

Figura 2 - Desenho esquemático da distribuição dos resultados de emissão dos veículos para um dado ano de fabricação.

Uma forma para diferenciar os veículos bem mantidos daqueles com manutenção deficiente é a análise das curvas de distribuição percentílica dos dados de emissões dos veículos de cada ano de fabricação.

Sendo impraticável um levantamento estatístico abrangente a partir da medição de emissões em ciclos padronizados de condução, ou mesmo em trânsito com equipamentos a bordo, este estudo vale-se das medições do Programa I/M-SP,. Esta abordagem é particularmente válida quando tomadas as variações das emissões em função das condições de conservação dos veículos e estatisticamente robusta por envolver milhões de medições, prestando-se à diferenciação entre tipos e até modelos de veículos, por idade.

\subsection{Conceitos utilizados na determinação dos fatores de emissão em massa}

A determinação das emissões em massa dos veículos em uso, conforme detalhado adiante, será feita a partir de correlações entre as escalas de concentrações médias obtidas no Programa I/M-SP e de emissões certificadas, tais como:

a) as emissões certificadas em veículos novos, ajustadas pelos fatores de deterioração disponíveis, geralmente obtidos no "Compilation of Air Pollution Emission Factors AP-42" da US EPA ${ }^{3}$, constituirão uma primeira tendência a ser considerada;

b) a escala da curva resultante será ajustada para ser superposta à curva das concentrações médias dos veículos em bom estado de manutenção (até o p90, que é o percentil abaixo do qual encontram-se $90 \%$ dos dados) obtidas no I/M-SP, fazendo-a coincidir nos pontos mais bem conhecidos e representativos;

c) os pontos que não coincidirem serão reposicionados sobre a curva de regressão das "concentrações I/M-SP" determinando novos fatores de emissão em massa;

d) as emissões de $\mathrm{CO}$ e $\mathrm{HC}$, em massa, resultantes são confrontadas contra referências teóricas baseadas no consumo de combustível e no balanço de carbono e, caso haja alguma incoerência, a escala é corrigida novamente por uma constante aplicada a todos os pontos.

Para os veículos do ciclo Otto (automóveis e motociclos) o AP-42 apresenta dois fatores de deterioração, a serem aplicados aos veículos com até 50.000 milhas $\left(\mathrm{FD}_{1}\right)$ e acima deste valor $\left(\mathrm{FD}_{2}\right)$.

A aplicação dos fatores norte-americanos para veículos do ciclo Otto é feita conforme as seguintes equações: 
$\mathrm{FE}_{\mathrm{usado}}=\mathrm{FE}_{\mathrm{novo}}+\left(\mathrm{FD}_{1} * \mathrm{M}\right)$, para veículos com até 50.000 milhas

$\mathrm{FE}_{\mathrm{usado}}=\mathrm{FE}_{\mathrm{novo}}+\mathrm{FD}_{1} * 5+\mathrm{FD}_{2} *(\mathrm{M}-5)$, para veículos com mais de 50.000 milhas

Onde:

$\mathrm{FE}_{\text {usado }}=$ fator de emissão do veículo usado

$\mathrm{FE}_{\text {novo }}=$ fator de emissão do veículo novo

$\mathrm{M}=$ milhagem acumulada (em milhares de milhas)

Para as emissões de material particulado dos veículos do ciclo Diesel, a compilação do AP-42 apresenta um mesmo fator para todos os tipos de veículo, cuja conversão para porcentagem a cada $10.000 \mathrm{~km}$ resulta em $1,09 \%$ para os veículos da fase $\mathrm{P} 4$ e anteriores e $0,89 \%$ para os da fase P5.

\subsection{Aplicação aos veículos Diesel}

A figura 3 apresenta as curvas percentílicas dos resultados de opacidade em aceleração livre obtidos nas inspeções de caminhões a diesel no ano exercício de 2012, como exemplo.

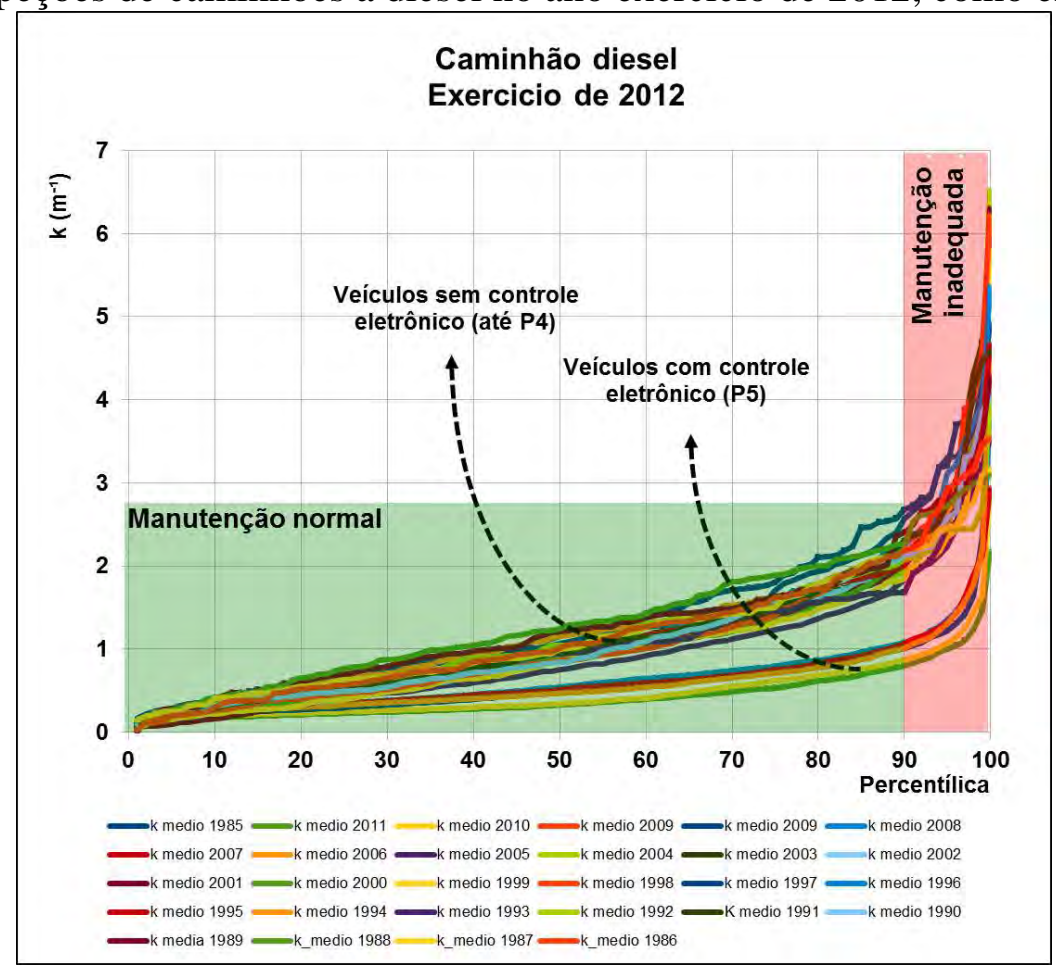

Figura 3 - Exemplo de curvas percentílicas com a separação dos grupos tecnológicos e de níveis de manutenção

Com base nestas curvas é determinado o ponto da curva de cada ano de fabricação e tipo de veículo que melhor corresponda ao ponto de corte para separar as duas populações, o qual se situa em um valor elevado, geralmente ao redor do p90. Este percentil é testado, a seguir, em comparação com o valor da respectiva mediana (ou p50), buscando-se uma correlação coerente, representada por um ano-modelo para o valor medido da emissão em função da idade do veículo. Este ano-modelo deve apresentar uma clara distinção entre a regressão dos valores de p90 e de p50 para cada idade (figura 4), que representam os dois grupos ilustrados na figura 3. Para percentis ainda mais elevados (p95 ou p98), as curvas obtidas da emissão em função da idade geralmente apresentam maiores variações, ou baixa coerência, com menores 
coeficientes de explicação " $\mathrm{R}^{2}$ ", devendo ser descartadas em favor de percentis menos elevados e mais coerentes.

Uma vez que existe uma variedade grande de combinações entre combustíveis e tecnologias, o detalhamento de cada caso seria muito extenso e repetitivo, de forma que serão utilizados os exemplos mais notáveis ou representativos que expliquem a metodologia para, ao final, serem apresentados os resultados de todos os casos.

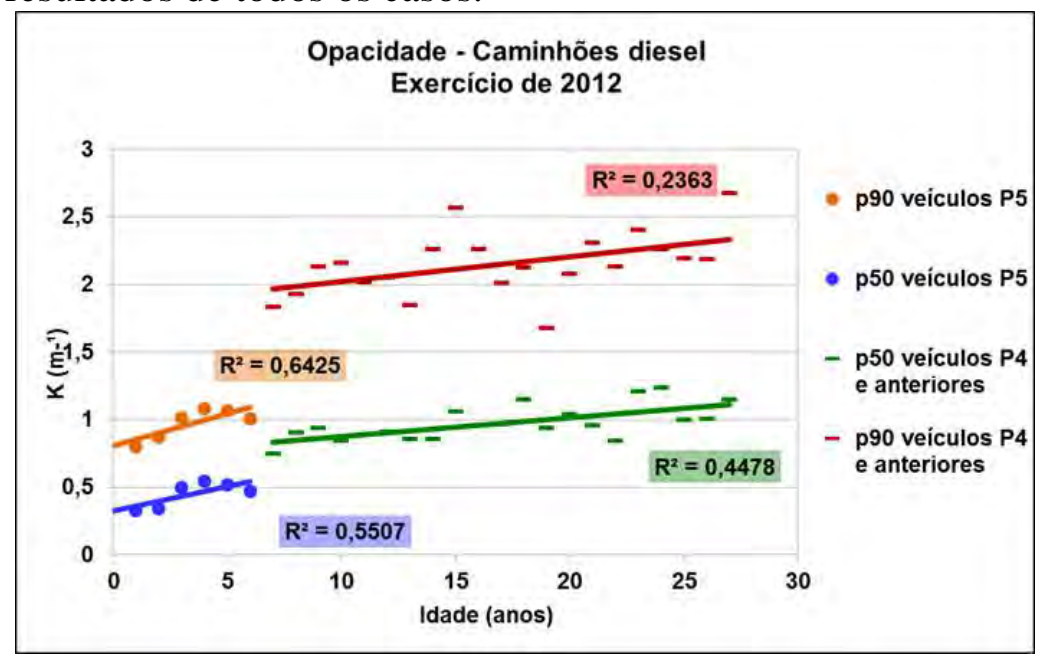

Figura 4 - Correlação da idade dos veículos com o p90 e a mediana

Uma vez identificado o percentil adequado à distinção dos estados de manutenção, isto é, o melhor ponto de distinção das distribuições estatísticas, define-se que os veículos mal mantidos serão representados pelos valores acima do ponto de distinção e os bem mantidos pelos valores abaixo deste ponto.

A análise comparativa tanto das curvas percentílicas dos veículos de diferentes idades quanto das regressões lineares fornece ainda a possibilidade de separação dos diferentes níveis tecnológicos do ponto de vista da "taxa de degradação" das emissões, quando se identificam tendências nitidamente diferentes. No caso dos caminhões, ilustrados nas figuras 3 e 4, verifica-se uma clara concordância entre as fases pré-PROCONVE, P1, P2, P3 e P4 nas duas regressões (do p50 e do p90), havendo uma distinção nítida para a fase P5 do PROCONVE (veículos com gerenciamento eletrônico do motor) nos dois casos.

Esta separação tecnológica é mais evidente entre as regressões dos valores de p90, correspondentes aos veículos altamente degradados, embora também se verifique com menor intensidade entre as regressões dos valores de p50, motivo pelo qual optou-se por unificar as curvas de degradação dos diversos níveis tecnológicos dos veículos em bom estado de manutenção, segregando os veículos com gerenciamento eletrônico. A análise resultante na figura 4 confirma o parâmetro p90 como o divisor entre os dois grupos de veículos, com manutenção adequada (abaixo de p90) e degradados ou adulterados (acima de p90).

\subsubsection{Emissões médias dos veículos em bom estado e dos mal mantidos}

Uma vez separados os grupos de níveis tecnológicos e de níveis de manutenção, são calculadas as médias dos valores de concentração situados abaixo do p90, correspondentes aos veículos com manutenção normal (90\% melhores), e acima do p90, representando os mal mantidos (10\% piores), para cada ano de fabricação, nos diferentes grupos tecnológicos reagrupados. A escolha do ponto de corte no p90 é bastante confiável para a distinção dos dois grupos e foi verificada experimentalmente em curvas reais. 
O gráfico das médias de emissões assim definidas, em função da idade - ou da quilometragem - permite o ajuste dos modelos, que serão a base da definição dos fatores de emissão dos veículos usados, como ilustrado na figura 5 para a opacidade em aceleração livre dos caminhões.

Com base nesta abordagem, o comportamento médio em termos de concentração de poluentes nos gases de escape pode ser estimado pelas equações de regressão (sejam elas lineares ou não) obtidas para cada grupo de veículos.

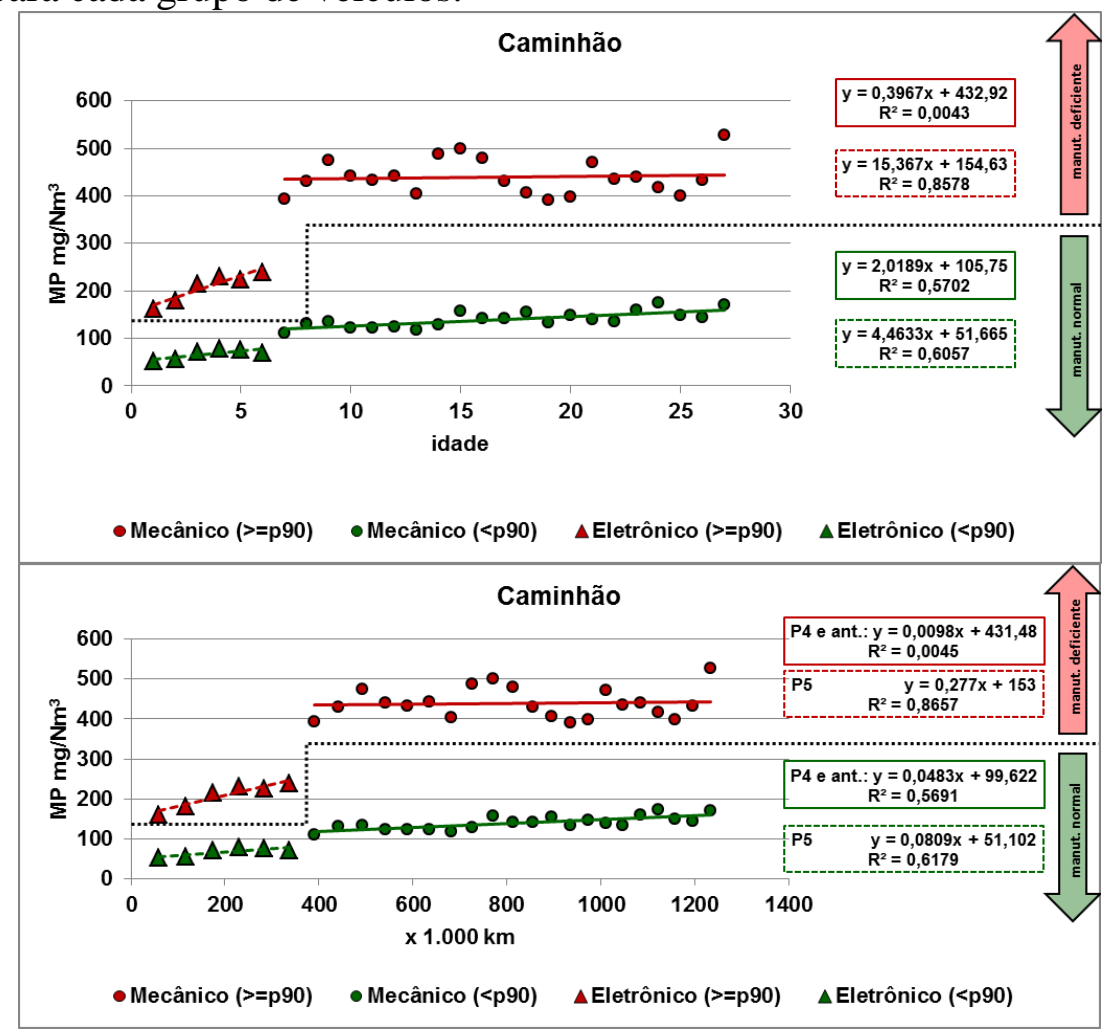

Figura 5 - Exemplos de equações de concentração em função da idade (acima) e da quilometragem (abaixo) para veículos com manutenção normal e degradados

\subsubsection{Representatividade dos ensaios realizados para a inspeção}

Até este ponto, as equações desenvolvidas refletem o comportamento da frota de veículos em termos das concentrações dos poluentes medidos nos gases de escapamento. Como em cada veículo as emissões em massa guardam uma relação própria com as concentrações, as variações destas nos regimes ensaiados refletem as variações decorrentes da qualidade da manutenção dos veículos e podem ser utilizadas para estimar as variaç̃es em massa das emissões em uso normal ou medidas em ciclos de condução padronizados, segundo o mesmo conceito utilizado no método de avaliação dos benefícios ambientais dos Programas I/ $\mathbf{M}^{2}$.

Um dos aspectos mais importantes deste trabalho é determinar o grau de representatividade dos ensaios de inspeção em relação aos de certificação. Por um lado, os ensaios realizados para inspeção devem ser rápidos, expeditos, de baixo custo e realizados em ambiente aberto, não controlado e com o combustível que estiver no veículo (combustível comercial). Por outro lado, os ensaios de certificação de tipo são sofisticados, realizados em ambiente com temperatura controlada, combustível de referência e com o veículo funcionando sob carga variável numa simulação de tráfego normal em ciclo de condução urbana padronizado. Avaliam a emissão de um modelo de veículo em estado de novo, que pode ser referenciado a seu nível tecnológico. Os resultados obtidos em ambos os ensaios não são diretamente 
conversíveis entre si, entretanto, o que se busca é a sua correlação em termos da avaliação dos efeitos do estado de conservação do veículo.

Cabe ressaltar que, no caso dos veículos do ciclo Diesel, a medição efetuada no Programa I/M-SP é a de opacidade, a qual deve ser convertida para concentração em massa de material particulado antes de gerar as curvas de regressão para comparação com os fatores de emissão dos veículos na condição "novo". A concentração de material particulado em $\mathrm{mg} / \mathrm{Nm}^{3}$ é obtida a partir da opacidade em $\mathrm{m}^{-1}$, conforme correlações experimentais ${ }^{4}$.

Adicionalmente, a maior parcela da emissão de particulados ocorre nos regimes de alto torque (parte superior do mapa do motor). A medição da opacidade máxima dos gases quando o motor passa por esta região do mapa, obtida no ensaio de aceleração livre, é uma forma simplificada de aferir a conformidade de um veículo em uso com as suas especificações originais. Entretanto, alguns fabricantes limitam a injeção em acelerações angulares elevadas nos motores com gerenciamento eletrônico, reduzindo a eficácia deste procedimento de teste, o que exige que a inspeção dos motores modernos seja baseada nas informações do OBD (On Board Diagnosis).

Complementarmente, ensaios realizados em dinamômetro seguindo o ciclo ETC - European Transient Cycle produzem valores de opacidade altamente variáveis com o torque instantâneo do motor que permitem a integração da curva temporal para o cálculo estimativo da massa de material particulado. Ordenando-se a opacidade de forma crescente, obtém-se esta massa de particulados integrada como função da opacidade, onde é possível observar a proporcionalidade entre ambas. De forma análoga, o valor máximo da opacidade medida em aceleração livre também é correlacionável à massa de particulados medida no ciclo de condução, sendo um bom indicador da massa total emitida em uso normal ${ }^{2}$.

\subsubsection{Fatores de emissão em massa}

Comparando-se os fatores de emissão certificados com os resultados das inspeções, observase que existem dois comportamentos distintos: o dos motores com gerenciamento eletrônico e os mecânicos, que exigem ajustes estatísticos separados para cada caso. Não há uma distinção nítida dos resultados do I/M-SP entre as diversas fases do PROCONVE, evidenciando claramente que os veículos das fases anteriores à P5 já perderam grande parte dos benefícios certificados, pois seus resultados se igualam na mesma reta de regressão, como indicado na figura 6 .

Os fatores de emissão de particulados dos motores Diesel começaram a ser certificados no Brasil a partir da fase P3, tendo havido um levantamento realizado com motores P2 para a preparação desta regulamentação. Por isso, é admissível a escolha da fase $\mathrm{P} 2$ como referência para a aplicação dos fatores de deterioração norte-americanos aos valores conhecidos e assim ajustados à curva do I/M-SP, pois os anteriores provêm de estimativas esparsas e de baixa representatividade estatística. 


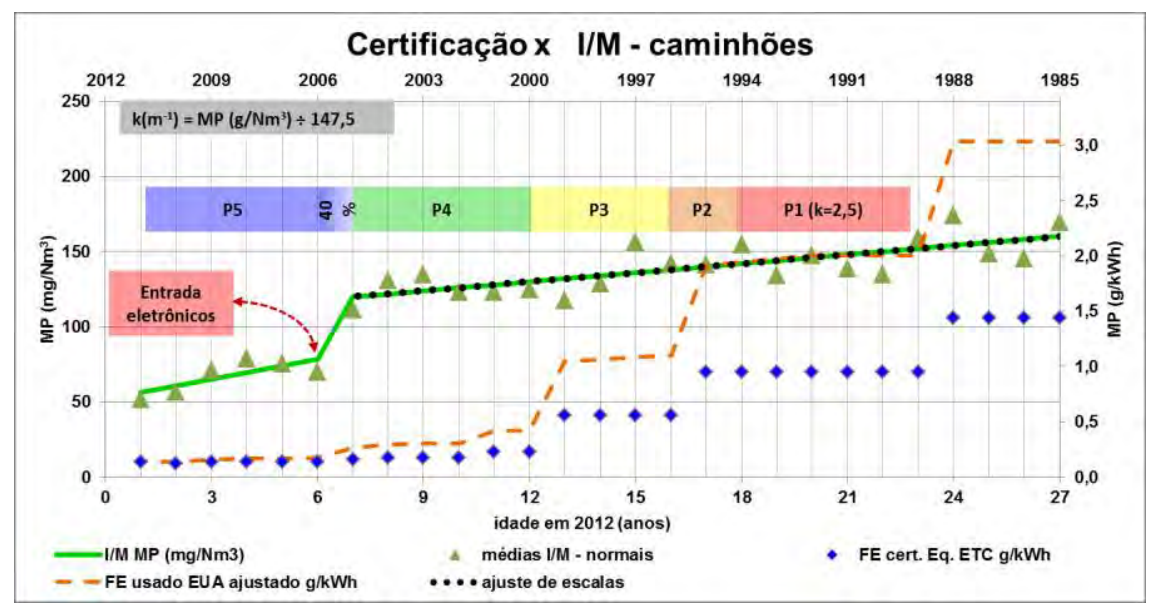

Figura 6 - Médias das concentrações de poluentes no I/M-SP em 2012, para veículos em condições normais de manutenção, e das emissões em massa na certificação, segundo a idade e o ano-fabricação.

Evidentemente, outros ajustes seriam possíveis - baseando-se nos veículos P3 ou mesmo P4 mas essas hipóteses foram descartadas, ao menos até que se obtenham os resultados de medições de laboratório a serem realizadas em veículos usados de cada fase, pois com os dados atuais resultariam em valores de emissão inferiores aos dos respectivos veículos novos das fases anteriores à utilizada para o ajuste (figura 7). Dados de medições em laboratório poderão, entretanto, determinar a existência de ajustes específicos para cada fase.

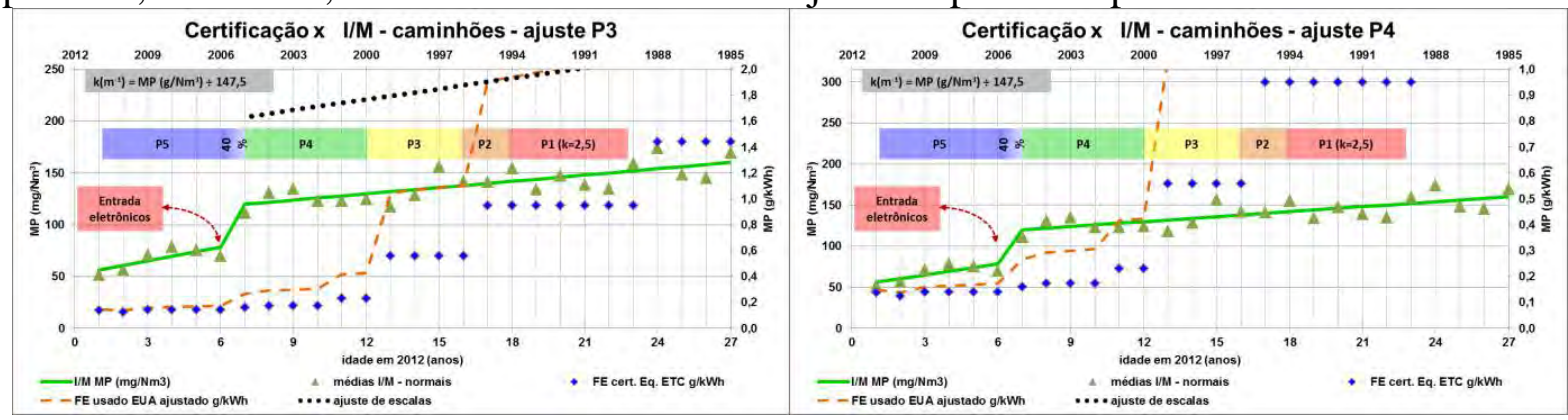

Figura 7 - Ajustes descartados por falta de coerência entre as fases

Desta análise resultaram, portanto, dois ajustes distintos:

a) Um para os motores anteriores à fase P4, "ancorado" pela fase P2;

b) Outro para os motores eletrônicos da fase P5, "ancorado" pelos veículos de um ano, para evitar que valores ajustados ficassem menores que os de certificação.

Uma vez definidos os "pontos de ancoragem" aceitáveis para as correspondências das curvas, os demais pontos em que o fator de emissão dos veículos afetados pelo FD americano não se ajusta à curva obtida no I/M-SP são trazidos para esta curva de regressão, como apresentado na figura 8 , considerando a fase P1 na qual as emissões de motores antigos medidas em g/kWh ainda são confiáveis.

Após o ajuste que leva aos fatores de emissão dos veículos normais, a estimativa para os veículos altamente degradados (mal mantidos) é dada pela curva dos valores obtidos em $\mathrm{g} / \mathrm{km}$ para os veículos normais multiplicados pela razão entre as concentrações estimadas pelas regressões, nos dois casos (alta emissão/normais), conforme mostrado na figura 8 . 
Novamente, obtém-se uma curva contínua para os "FE_degradados", cuja coerência com os valores das concentrações I/M-SP está mantida.

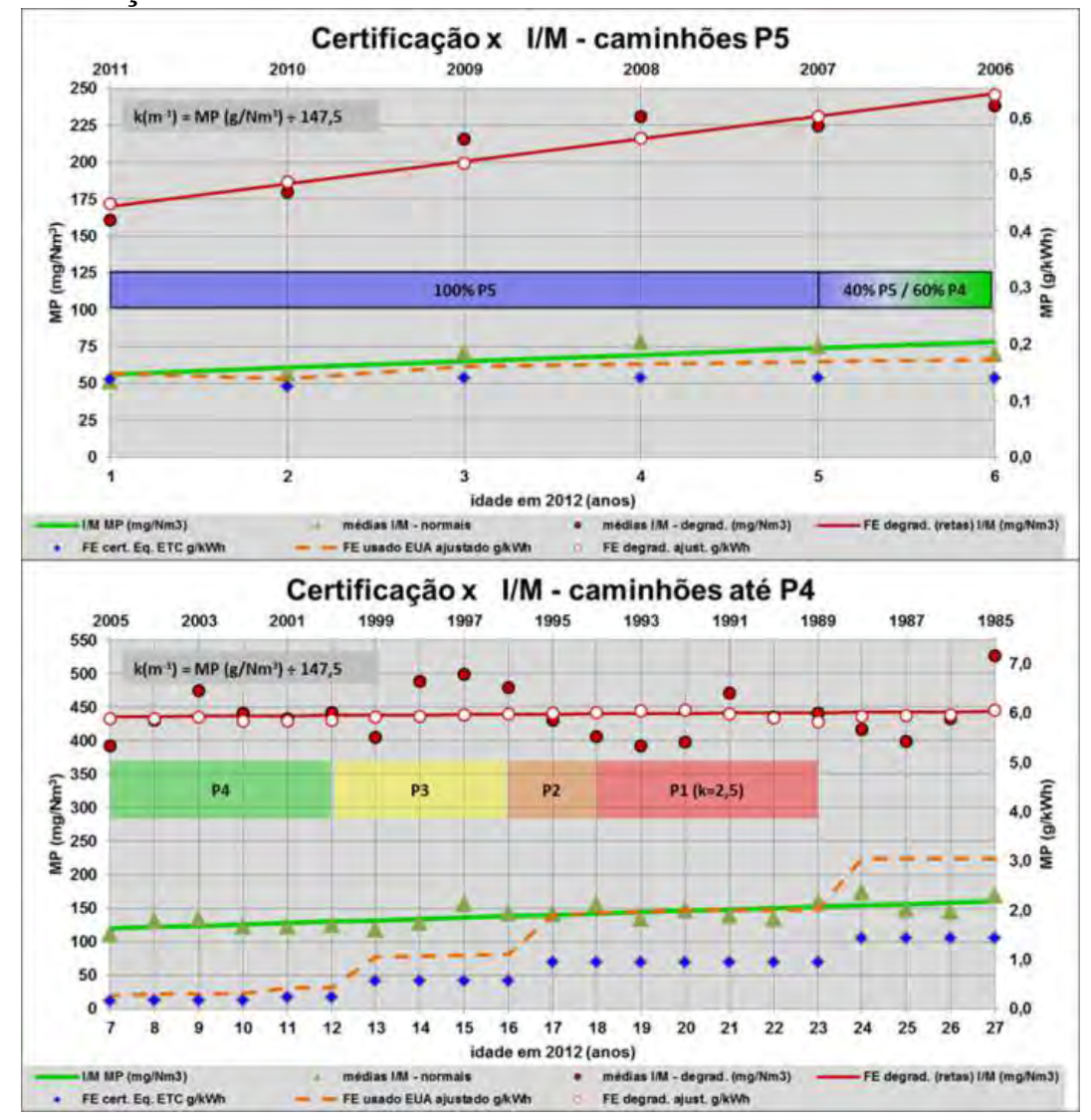

Figura 8 - Ajuste final da curva dos fatores de emissão de MP dos veículos usados à curva determinada no I/M-SP

\subsection{Aplicação aos veículos com motor do ciclo Otto}

No caso dos automóveis a gasolina, em que existe uma longa e ininterrupta série de dados de emissão, medida em $\mathrm{g} / \mathrm{km}$ e com um histórico de evolução contínua, é possível obter uma curva única de degradação (idealmente uma curva do tipo "S") para os veículos de todas as idades e padrões tecnológicos, com alta aderência aos dados. Apesar das exigências para as certificações oficiais serem definidas em etapas que podem apresentar saltos tecnológicos significativos, esta continuidade pode decorrer da penetração dessas tecnologias no mercado em extensão gradualmente crescente. Neste caso, a redução contínua das emissões de $\mathrm{CO}$ e HC se evidencia a partir da implantação do Programa de Economia de Combustível - PECO e mais tarde do PROCONVE, que promoveram o aprimoramento dos carburadores entre as idades de 20 a 29 anos (ano-base 2012), depois a fase L2 com a entrada da injeção eletrônica ou, alternativamente, do carburador associado ao catalisador de oxidação e, finalmente, a adoção dos sistemas com controle eletrônico em circuito fechado e catalisadores de oxiredução para as idades menores que 15 anos, como ilustrado na figura 9. 


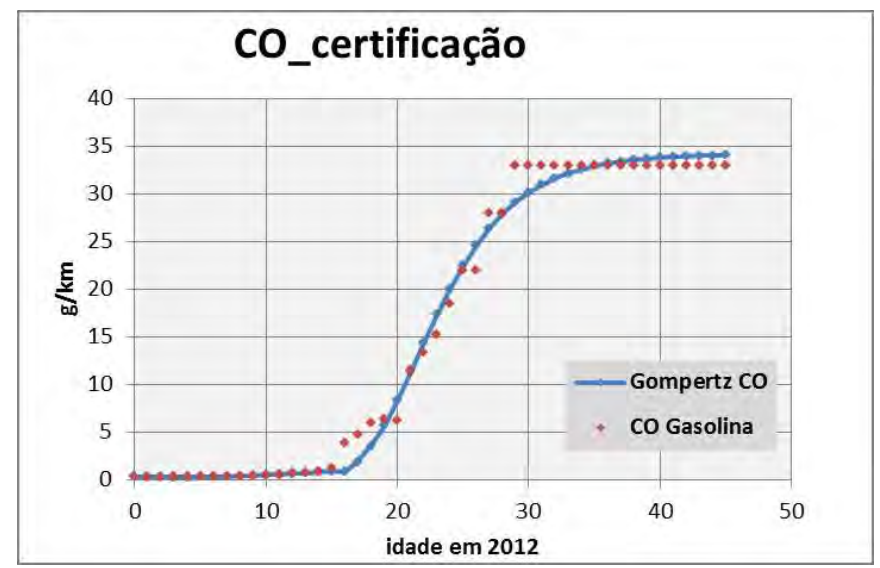

Figura 9 - Evolução dos fatores de emissão de veículos novos a gasolina

\subsubsection{Representatividade dos ensaios realizados para a inspeção}

Da mesma forma descrita para os veículos Diesel, é necessário determinar o grau de representatividade dos ensaios de $\mathrm{CO}$ e $\mathrm{HC}$ em marcha lenta realizados na inspeção em relação aos ensaios de certificação de veículos novos em ciclo de condução padronizado. Também nesse caso, estas emissões são medidas em concentração $(\%$ em volume para $\mathrm{CO}$ e ppm para HC) com o motor trabalhando em regime de marcha lenta, tomado como referência por ser uma das condições nas quais há maior sensibilidade às falhas de manutenção que interferem na combustão e no funcionamento dos sistemas de controle de emissão. Assim, como comentado para os motores Diesel, estes ensaios também não são conversíveis diretamente entre si, por causa das diferentes condições de funcionamento do veículo em cada um, entretanto o que se busca é a sua correlação em termos da avaliação dos efeitos do estado de conservação do veículo, especialmente por que esta seria uma das poucas formas de se conseguir um elevado número de avaliações de veículos da frota circulante. A semelhança dos comportamentos estatísticos dos resultados obtidos nos dois casos é a chave para a solução deste problema, o que é mostrado a seguir.

Para os automóveis do ciclo Otto a gasolina, que constituem a maior frota avaliada e a que permeia a maior faixa de idades e todas as etapas tecnológicas do PROCONVE, foi possível levantar com precisão o tipo de curva que rege o comportamento da evolução tecnológica já associada à degradação das emissões de $\mathrm{CO}$ e de $\mathrm{HC}$ ao longo do tempo.

A partir dos fatores médios de emissão publicados pela CETESB no seu "Relatório de Qualidade do Ar no Estado de São Paulo", é possível verificar que tanto a evolução das emissões dos automóveis novos a gasolina quanto as concentrações medidas nos automóveis usados, no âmbito do Programa I/M-SP (sejam de CO ou de HC) seguem curvas contínuas, reduzindo-se gradativamente desde o início do PROCONVE em função das suas exigências e do consequente aprimoramento tecnológico, associado à penetração dos novos modelos no mercado.

A figura 10 apresenta, como exemplo, as médias das concentrações de CO e de HC dos veículos Otto a gasolina com manutenção rotineira, bem mantidos e conservados ${ }^{1}$, que foram inspecionados em 2012 no I/M-SP, ao lado das emissões em massa dos mesmos poluentes

\footnotetext{
${ }^{1}$ Foram consideradas as médias dos valores de concentração de $\mathrm{CO}$ e $\mathrm{HC}$ situados abaixo do percentil p90, correspondentes aos veículos com manutenção normal (90\% melhores), e acima do p90, representando os mal mantidos ( $10 \%$ piores), para cada grupo definido, como mostrado anteriormente para os veículos Diesel.
} 
determinadas no processo de certificação. Nela fica evidente o comportamento de ambas as curvas de crescimento na forma de uma sigmóide (curvas tipo S).

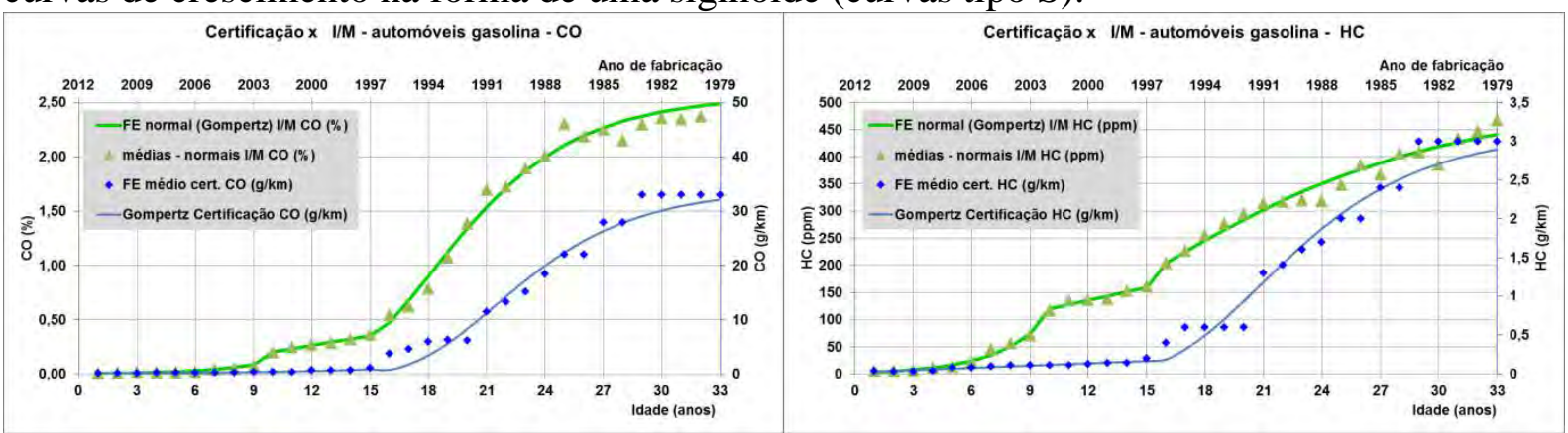

Figura 10 - Médias das concentrações de poluentes no I/M-SP em 2012, para veículos em condições normais de manutenção, e das emissões em massa na certificação, segundo a idade e o ano-fabricação.

Os dados aderiram quase perfeitamente a uma curva Gompertz, mostrando uma alta coerência entre os resultados do veículo novo (certificação) e do usado (concentração medida no I/M), validando os valores obtidos do I/M-SP como um instrumento representativo dos fatores de emissão em massa dos veículos usados. Portanto, este fato evidencia que a correlação estatística entre os dois resultados pode fornecer subsídios importantes para a avaliação da degradação das emissões nos veículos usados. Entretanto, ressalta-se que os desvios observados entre a curva estatística e os pontos reais são aceitáveis nos trechos superior e médio da curva, porém inaceitáveis no inferior, onde os valores reais são demasiadamente baixos. A regressão sugere erroneamente um patamar de 8 anos com valores quase nulos, o que não é verdade, portanto, o trecho inferior da curva foi estimado por uma regressão distinta para corrigir a anomalia.

O mesmo comportamento foi observado para o $\mathrm{CO}$ e HC, tanto nos veículos com conservação normal, como para aqueles com manutenção deficiente ou adulterados (emissão acima de p90), como mostra a figura 11.

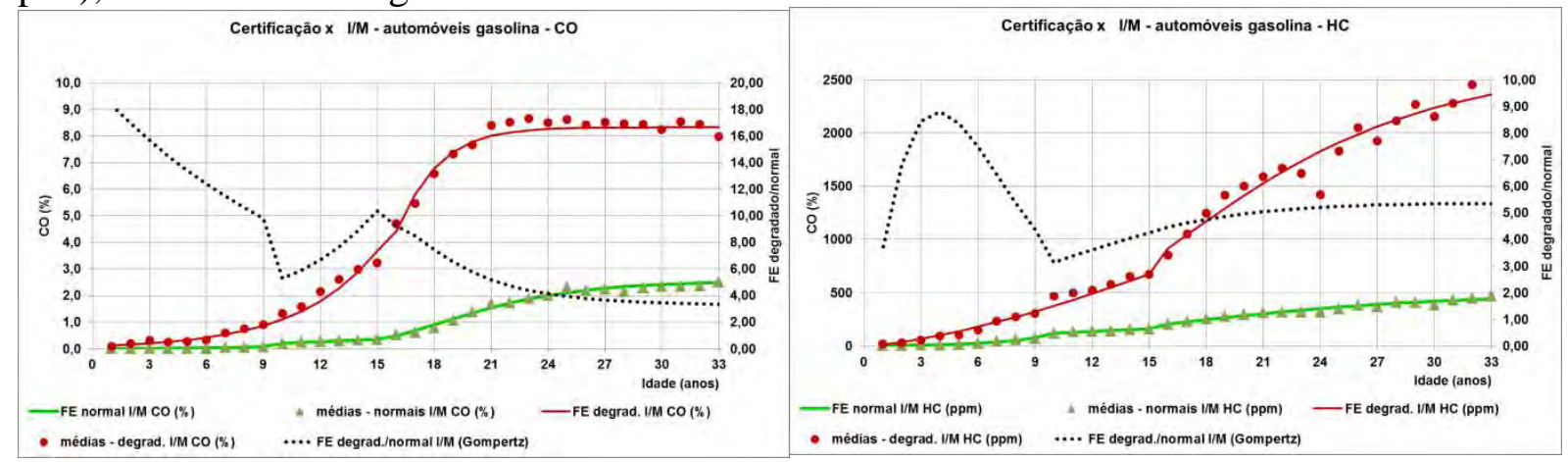

Figura 11 - Médias de CO e HC (ppm) dos veículos ciclo Otto a gasolina inspecionados em 2012 segundo o ano-fabricação.

A razão entre os valores obtidos para os veículos com manutenção deficiente e normal, que será utilizada para cálculo dos fatores de emissão dos veículos degradados, é obtida a partir dessas regressões a fim de caracterizar o comportamento médio daquela categoria de veículo e idade, excluindo as variações dos valores reais observadas ponto a ponto.

Para os veículos flex, GNV e motociclos, as respectivas séries históricas dos dados não são tão extensas nem tão representativas quanto a dos veículos a gasolina, muito mais numerosos 
e com ampla gama de idades e padrões tecnológicos. Por isso, estes casos foram ajustados como nos veículos Diesel, por curvas mais simples e por trechos.

\subsubsection{Fatores de emissão em massa}

Foram selecionados fatores de deterioração do AP-42, buscando grupos tecnológicos semelhantes aos das fases do PROCONVE e PROMOT, com base nos fatores de emissão dos veículos novos e em características construtivas dos veículos, como por exemplo, injeção eletrônica ou carburador, presença de catalisador, tamanho de motor (no caso dos motociclos) etc.. Esta abordagem foi necessária como ponto de partida para balizar as estimativas de fatores de emissão brasileiros, a qual será ajustada pelos resultados estatísticos indicados pelo Programa I/M de São Paulo.

Para facilitar a aplicação, as idades foram associadas à quilometragem acumulada $^{5}$ e os fatores selecionados foram recalculados de forma a representar um porcentual de acréscimo a cada $10.000 \mathrm{~km}$, sobre os respectivos valores base, apresentados na tabela 1, os quais podem ser aplicados sobre os fatores de emissão obtidos nas certificações de veículos brasileiros.

Tabela 1 - Fatores deterioração norte-americanos selecionados para $10.000 \mathrm{~km}$

\begin{tabular}{|c|c|c|c|c|c|}
\hline $\begin{array}{l}\text { Tipo de } \\
\text { veículo }\end{array}$ & Poluente & $\begin{array}{c}\text { Ano de fabricação } \\
\text { (Brasil) }\end{array}$ & $\begin{array}{c}\text { Ano de fabricação } \\
\text { (EUA) }\end{array}$ & FD $_{1}$ & $\mathbf{F D}_{2}$ \\
\hline \multirow{15}{*}{$\begin{array}{c}\text { Automóveis } \\
\text { a gasolina }\end{array}$} & \multirow{6}{*}{$\mathrm{CO}$} & $1979-1985$ & $1968-1969$ & $2,8 \%$ & $2,8 \%$ \\
\hline & & $1986-1987$ & $1972-1974$ & $3,6 \%$ & $3,6 \%$ \\
\hline & & $1988-1991$ & $1970-1971$ & $4,6 \%$ & $4,6 \%$ \\
\hline & & $1992-1996$ & $1975-1979$ & $8,6 \%$ & $8,6 \%$ \\
\hline & & $1997-2000$ & 1984 & $23,3 \%$ & $23,3 \%$ \\
\hline & & $2001-2011$ & 1992 e posterior & $41,9 \%$ & $41,9 \%$ \\
\hline & \multirow{9}{*}{$\mathrm{HC}$} & $1979-1983$ & pré-1968 & $1,5 \%$ & $1,5 \%$ \\
\hline & & $1984-1988$ & $1968-1969$ & $3,5 \%$ & $3,5 \%$ \\
\hline & & $1989-1991$ & $1970-1971$ & $7,7 \%$ & $7,7 \%$ \\
\hline & & $1992-1995$ & $1975-1979$ & $16,4 \%$ & $16,4 \%$ \\
\hline & & 1996 & $(*)$ & $20,2 \%$ & $20,2 \%$ \\
\hline & & 1997 & 1980 & $35,4 \%$ & $35,4 \%$ \\
\hline & & $1998-1999$ & 1983 & $23,0 \%$ & $70,7 \%$ \\
\hline & & 2000 & 1996 & $21,3 \%$ & $80,8 \%$ \\
\hline & & $2001-2011$ & 1998 e posterior & $24,3 \%$ & $92,2 \%$ \\
\hline \multirow{7}{*}{ Motociclos } & \multirow{3}{*}{$\mathrm{CO}$} & $1980-2002$ & & $2,5 \%$ & $2,5 \%$ \\
\hline & & $2003-2008$ & & $2,0 \%$ & $2,0 \%$ \\
\hline & & $2009-2011$ & & $1,2 \%$ & $3,6 \%$ \\
\hline & \multirow{4}{*}{$\mathrm{HC}$} & $1980-2002$ & & $1,2 \%$ & $1,2 \%$ \\
\hline & & $2003-2005$ & & $0,7 \%$ & $0,7 \%$ \\
\hline & & $2006-2008$ & & $0,2 \%$ & $0,2 \%$ \\
\hline & & $2009-2011$ & & $0,1 \%$ & $0,3 \%$ \\
\hline
\end{tabular}

(*) média ponderada entre os fatores de 1975-1979 e de 1980, considerando a entrada gradual no mercado da fase L3, uma vez que não foram encontrados fatores de emissão do veículo novo compatíveis com os fatores de certificação nacionais. 
Como a tecnologia flex não consta da compilação AP-42 da EPA, o fator AMA (Approved Mileage Accumulation test ${ }^{6}$ ) estimado pela CETESB para $80.000 \mathrm{~km}$, foi tomado como base para os fatores de deterioração desses veículos, dividido por 7,4 para resultar em uma taxa de degradação para cada $10.000 \mathrm{~km}^{2}$. Para o CO esta premissa se mostrou adequada para os veículos mais novos (L5) e subestimada para os mais antigos, enquanto que para o HC ela se manteve adequada para todos os anos de fabricação.

Os veículos que utilizam GNV, na sua grande maioria foram convertidos predominantemente a partir de veículos a gasolina (veículos fabricados antes de 2007) ou flex (a partir de 2007). Como a conversão é um procedimento feito após a fabricação do veículo, e não se registra o fator de emissão do veículo recém convertido, os fatores de deterioração aplicados são os mesmos dos veículos originais correspondentes. No caso de veículos fabricados originalmente para utilização alternativa de GNV, os fatores de emissão são certificados para todos os combustíveis utilizáveis, incluindo a determinação dos fatores de deterioração. Cabe ressaltar que os veículos convertidos para GNV apresentam uma proporção elevadíssima de desconformidade ${ }^{7}$, representando mais de $65 \%$, dependendo do ano de fabricação.

No caso dos motociclos, os fatores de deterioração apresentados no AP-42 são demasiadamente elevados, coerentes com o consumo de combustível de uma motocicleta grande. Depois de corrigidos para um consumo mais realista para a frota brasileira, composta por motociclos menores e de uso mais intenso, os resultados se tornaram coerentes para os motociclos bem mantidos, mas ainda parecem elevados demais no caso dos veículos mal mantidos. Por isso, estes valores devem ser aprimorados por ensaios de veículos usados em dinamômetro.

\subsubsection{Ajuste dos fatores de emissão obtidos com os FD americanos}

Os fatores de emissão calculados a partir dos fatores de deterioração norte-americanos foram também plotados em gráfico, juntamente com os dados medidos no $\mathrm{I} / \mathrm{M}$ e os fatores de emissão de certificação anteriormente expostos (figura 10), permitindo um primeiro ajuste dos eixos, de forma a buscar um ou mais pontos de ancoragem entre as curvas do I/M e do veículo deteriorado. Os trechos buscados para a ancoragem devem ser sempre aqueles para os quais haja uma correspondência clara entre a tecnologia nacional e a norte-americana (idades entre 10 e 15 anos - Fase L3), e onde os fatores de emissão dos veículos novos sejam bem conhecidos, como apresentado na figura 12.

A seguir, é introduzido um primeiro fator de ajuste para os pontos em que o fator de emissão dos veículos afetados pelo FD americano não se ajusta à curva obtida no I/M-SP, trazendo-os para a curva de regressão obtida, como indicado pelas setas na figura 2.10.

\footnotetext{
${ }^{2}$ Segundo o procedimento NBR 14008, a determinação do FD é dada pela variação da emissão entre 6 e $80 \mathrm{mil} \mathrm{km}$, isto é, em um intervalo de $74 \mathrm{mil} \mathrm{km}$. Para efeito deste trabalho, foram tomadas as medianas dos valores de $\mathrm{FD}_{\mathrm{AMA}}$ disponíveis determinados nos processos de certificação.
} 


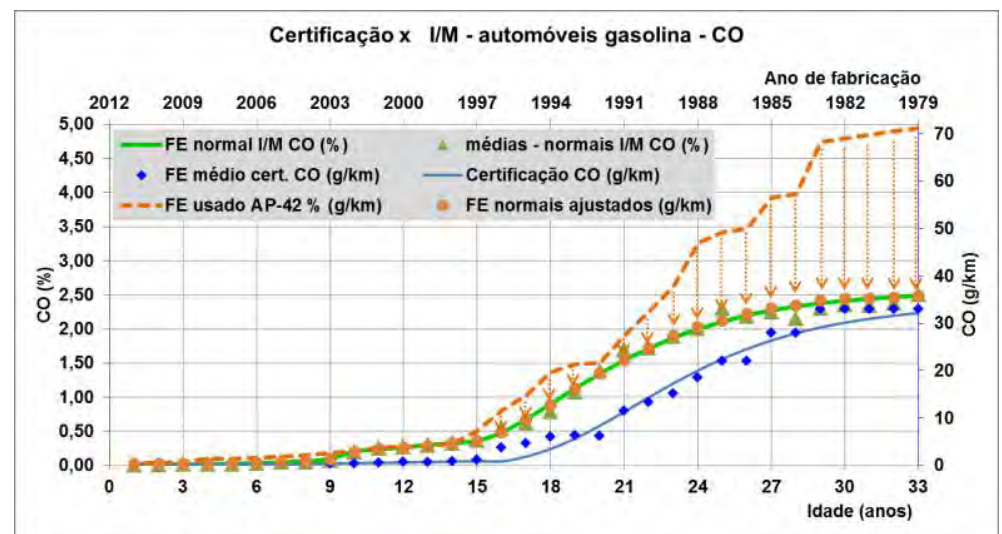

Figura 12 - Ancoragem inicial entre a curva de fatores de emissão em $\mathrm{g} / \mathrm{km}$ e concentração

Uma vez feito o cálculo dos fatores de emissão dos veículos normais, a estimativa para os veículos altamente degradados (mal mantidos) é dada pela curva dos valores obtidos em $\mathrm{g} / \mathrm{km}$ para os veículos normais multiplicados pela razão entre as concentrações estimadas pelas regressões, nos dois casos (alta emissão/normais), conforme mostrado na figura 13. Novamente, obtém-se uma curva contínua para os "FE_degradados", cuja coerência com os valores das concentrações I/M-SP está assegurada.

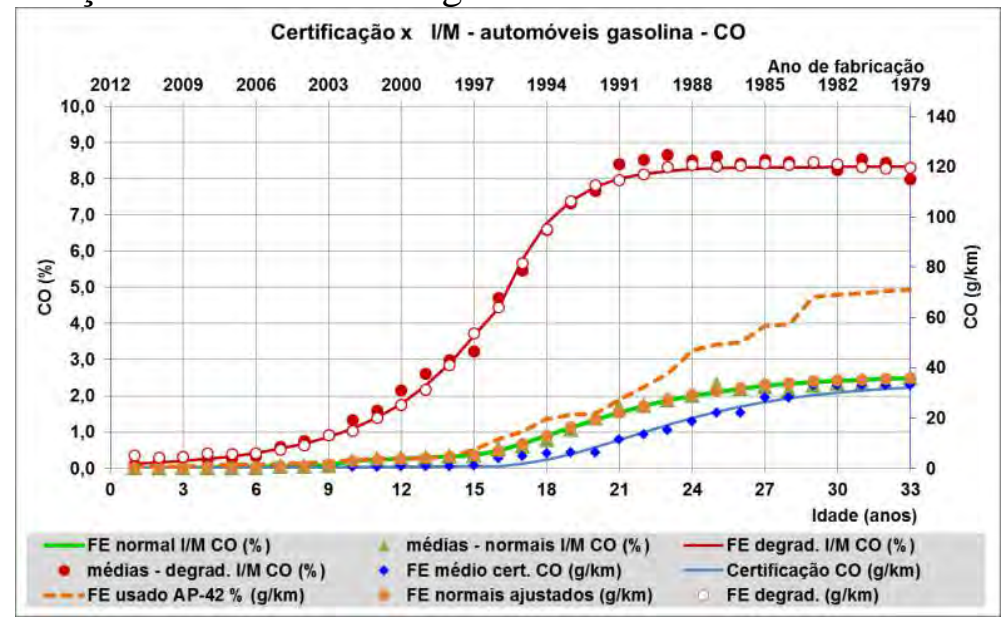

Figura 13 - Ajuste da curva dos fatores de emissão de CO dos veículos excessivamente deteriorados

No caso dos motociclos, não foi possível obter uma única "ancoragem das curvas" para todas as idades, possivelmente devido à precariedade dos dados anteriores ao PROMOT. A correspondência entre as concentrações medidas no I/M-SP e os fatores de emissão em uso normal mostrou-se diferente para cada nível tecnológico, sendo necessário dividir o gráfico por faixa de idades, como também ocorreu no caso dos motores Diesel, discutido anteriormente.

Os fatores de emissão dos motociclos novos são bem conhecidos, e publicados oficialmente pela CETESB apenas a partir do ano 2003 (fase M1 do PROMOT). Como os resultados das inspeções apresentam uma boa correlação linear, sem qualquer descontinuidade para todos os motociclos anteriores a 2003, foram adotados neste trabalho os valores de emissão medidos pela EnvironMentality em 1998 em uma motocicleta Honda CG 125, fabricada naquele ano, único valor disponível para motociclos brasileiros, mas altamente representativo dos 
motociclos existentes naquela época. Cabe ressaltar que os fatores de emissão adotados no inventário atual do Ministério do Meio Ambiente para estes modelos são valores americanos muito elevados, que não refletem a realidade brasileira, e por isso foram desconsiderados neste trabalho. A figura 14 apresenta as comparações dos resultados do I/M para os motociclos em bom estado de manutenção (média dos valores abaixo de p90), os valores em $\mathrm{g} / \mathrm{km}$ dos veículos novos e estes valores afetados dos FD americanos, onde se identifica a necessidade de dois ajustes: um para o PROMOT e outro para os veículos sem controle de emissão.
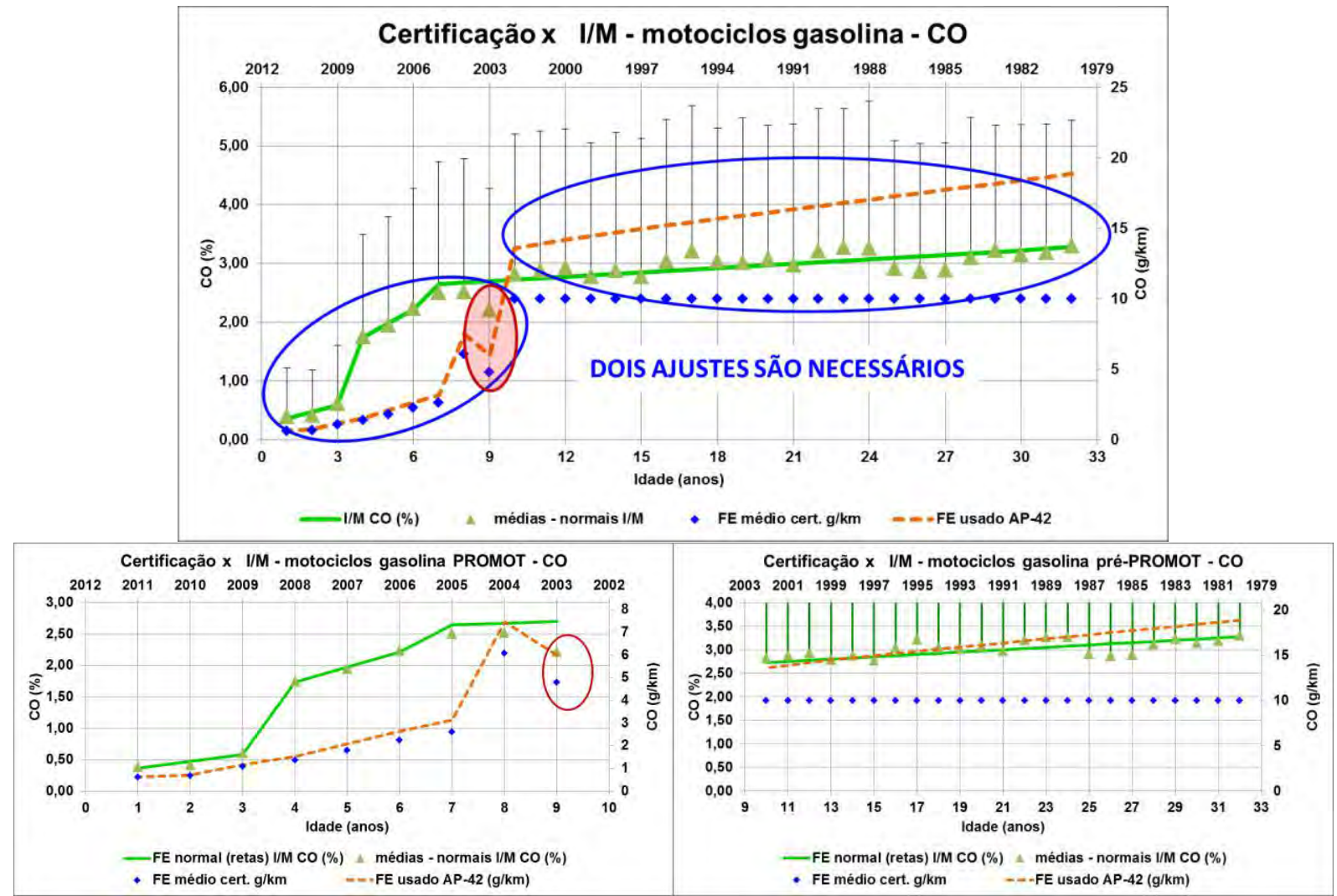

Figura 14 - Exemplo de ancoragem entre a curva de fatores de emissão em $\mathrm{g} / \mathrm{km} \mathrm{e}$ concentração com dois ajustes distintos para motociclos

Note-se que, para os motociclos abrangidos pelo PROMOT, a ancoragem foi feita com base em 2004 sobre a curva de regressão (indicado pelas elipses vermelhas), porém considerando efetivamente a média real em 2003. Estes dois pontos apresentam fatores de emissão de certificação distintos, embora ambos estejam em conformidade com os limites M1, mas bastante coerentes com as concentrações medidas no I/M-SP, fato assim justificado pelas inspeções e atribuído à entrada de novas marcas no mercado em 2004.

O Programa de Inspeção e Manutenção evidencia claramente que os motociclos da fase M1 perderam totalmente as características certificadas, pois seus resultados se igualam aos resultados dos modelos anteriores, anteriores ao controle de emissões, na mesma reta de regressão. Já na fase M2, os fatores de deterioração são muito mais altos do que o esperado a partir da aplicação dos FD americanos, porém mantendo ainda uma parte dos benefícios dos controles de emissão aplicados, levando à conclusão de que as alterações efetuadas nessa fase para atendimento aos seus limites de certificação não apresentaram a durabilidade esperada.

Finalmente na fase M3, as tecnologias empregadas surtiram efeitos melhores e aparentemente mais duradouros, ainda coerentes com os FD americanos, porém estes veículos ainda eram 
relativamente novos no ano 2012, em estudo, e não há dados mais recentes porque o Programa I/M-SP foi infelizmente descontinuado.

\subsubsection{Limitação dos fatores de emissão obtidos mediante comparação com o consumo de combustível}

Uma última condição de contorno é verificar que a existência de carbono proveniente do combustível seja suficiente para a formação das massas de $\mathrm{CO}$ e $\mathrm{CO}_{2}$. Para isso, verifica-se a coerência dos fatores de emissão resultantes com o consumo de combustível estimado dos veículos, através da curva que relaciona o porcentual em volume de $\mathrm{CO}$ e $\mathrm{CO}_{2}$ nos níveis determinados no I/M-SP com a massa de CO resultante da queima ${ }^{3}$.

Assim, plotando-se no mesmo gráfico os valores máximos de $\mathrm{CO}$, calculados teoricamente em $\mathrm{g} / \mathrm{km}$ para diferentes estimativas de consumo, e as concentrações médias determinadas no I/M-SP, pode-se avaliar se existe coerência entre os valores calculados da emissão em $\mathrm{g} / \mathrm{km}$ e o consumo admitido como plausível para o veículo considerado (figura 15).

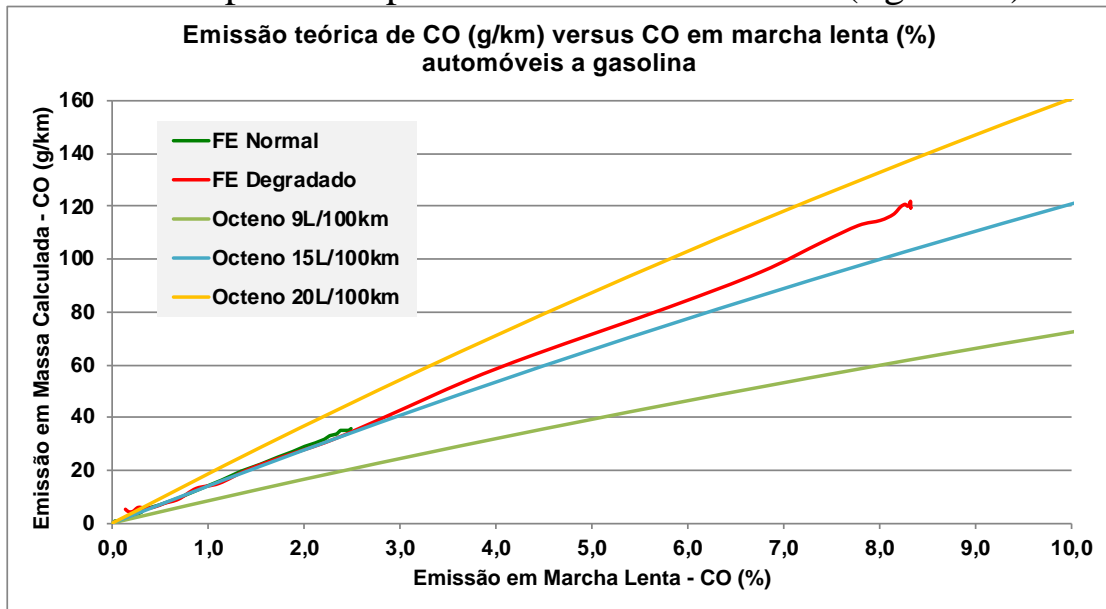

Figura 15 - Verificação da compatibilidade entre os fatores de emissão calculados e o consumo esperado de combustível para automóveis a gasolina

No caso dos automóveis flex, a concentração de $\mathrm{CO}$ em marcha lenta é muito baixa, o que torna este cálculo impreciso. Por esta razão os ajustes da ancoragem entre as curvas também consideraram que o FE mínimo possível deve ser igual ou superior ao valor de certificação. Neste caso, optou-se por adotar o último ano da fase L4 como "ponto de ancoramento" da série para todos os modelos mais antigos tornando o ponto 2008 real verde coincidente com o valor estimado pelos fatores americanos, que foram mantidos inclusive para os veículos mais novos, como mostrado na figura 16. Para os modelos mais recentes, cuja degradação ainda é incipiente a solução mais adequada é manter a degradação americana aplicada sobre os fatores de certificação brasileiros até que novos dados sejam levantados.

\footnotetext{
${ }^{3}$ Assume-se que a reação entre $\mathrm{O}_{2}$ e combustível é feita sem sobra de $\mathrm{O}_{2}$, que implica em que a formação do CO, quando existente, decorre da falta de ar. Com isso calcula-se a concentração de $\mathrm{CO}_{2}$ nos gases encontrados no escape, para cada razão ar/combustível resultante em função de concentrações de $\mathrm{CO}$ pré-estabelecidas. Com as concentrações de $\mathrm{CO}$ e $\mathrm{CO}_{2}$ em volume, calcula-se a emissão em gramas de CO por grama de combustível queimado, através da ponderação das concentrações em volume pelos pesos moleculares do $\mathrm{CO}$ e do combustível. Esta massa de $\mathrm{CO}$ emitida foi associada a valores de consumo admissíveis, em $1 / 100 \mathrm{~km}$, e assim determinada um uma curva limite para a emissão em massa de $\mathrm{CO}$ em função da \% de $\mathrm{CO}$ medida no I/M.
} 


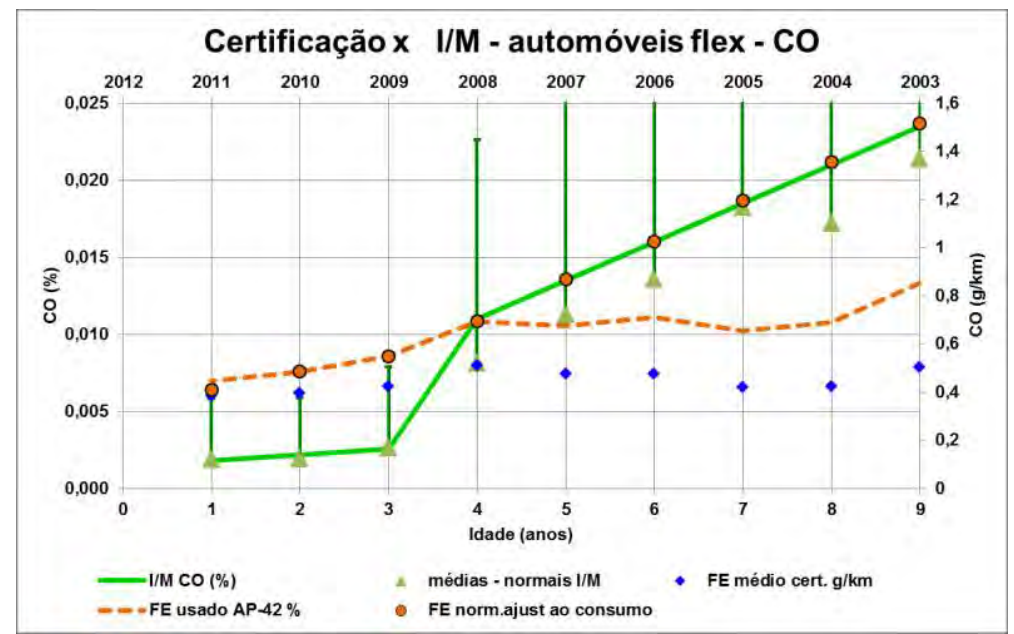

Figura 16 - Ancoragem final entre a curva de fatores de emissão em $\mathrm{g} / \mathrm{km}$ e concentração para automóveis flex

Esta análise levou à escolha dos melhores pontos de ancoragem entre as curvas, de forma que não fossem ultrapassados os valores plausíveis de consumo de combustível para os automóveis a gasolina e flex, por exemplo.

É oportuno ressaltar que as concentrações de CO tomadas em marcha lenta costumam ser superiores às observadas com o motor sob carga, de forma que esta comparação deve ser tomada apenas como uma referência indicativa da coerência entre as escalas de correlação determinadas e indicadora dos limites superiores da degradação das emissões dos veículos sob utilização real em contraposição aos fatores determinados pelos ensaios AMA que representam os limites mínimos, isto é, em condições ideais.

No exemplo da figura 15, as emissões calculadas para os automóveis bem mantidos mostraram-se compatíveis com veículos que gastem 15 litros de combustível para cada 100 $\mathrm{km}$ percorridos (ou $6,7 \mathrm{~km} / \mathrm{L}$ ), o que é admissível para uso urbano. Já os mal mantidos mostram uma ligeira elevação do consumo, ficando próximo dos $17 \mathrm{~L} / 100 \mathrm{~km}(5,9 \mathrm{~km} / \mathrm{L})$, o que ainda é compatível com o que se verifica na prática.

No caso da emissão de $\mathrm{HC}$, utilizou-se técnica semelhante, porém baseada em outras premissas:

- admite-se que a falha constante de ignição de um cilindro, num motor típico de 4 cilindros, represente um defeito grave, difícil de ser aceito por um usuário, e certamente levaria à reprovação do veículo pela emissão de HC;

- neste caso, a quantidade de combustível não queimado expelida pelo tubo de escapamento seria $25 \%$ do consumo de combustível, a ser admitido como limite máximo da emissão de HC de um veículo degradado;

A correlação entre as medições de $\mathrm{HC}$ em marcha lenta e os valores estimados em $\mathrm{g} / \mathrm{km}$ balizada nas duas premissas anteriores e no consumo de $15 \mathrm{~L} / 100 \mathrm{~km}$ para os veículos degradados levou ao teto de $21 \mathrm{~g}$ de $\mathrm{HC} / \mathrm{km}$ e $3,8 \mathrm{~g}$ de $\mathrm{HC} / \mathrm{km}$ para os veículos antigos em bom estado de manutenção. Este valor corresponde a 3,5\% do consumo de combustível e representa $27 \%$ de deterioração sobre os valores padrão da CETESB para os veículos préPROCONVE, atualmente com 33 anos de idade, como mostrado na figura 17. A curva de fatores de deterioração assim obtida a partir do I/M mostra-se como uma excelente substituta para a curva dos FD americanos. 


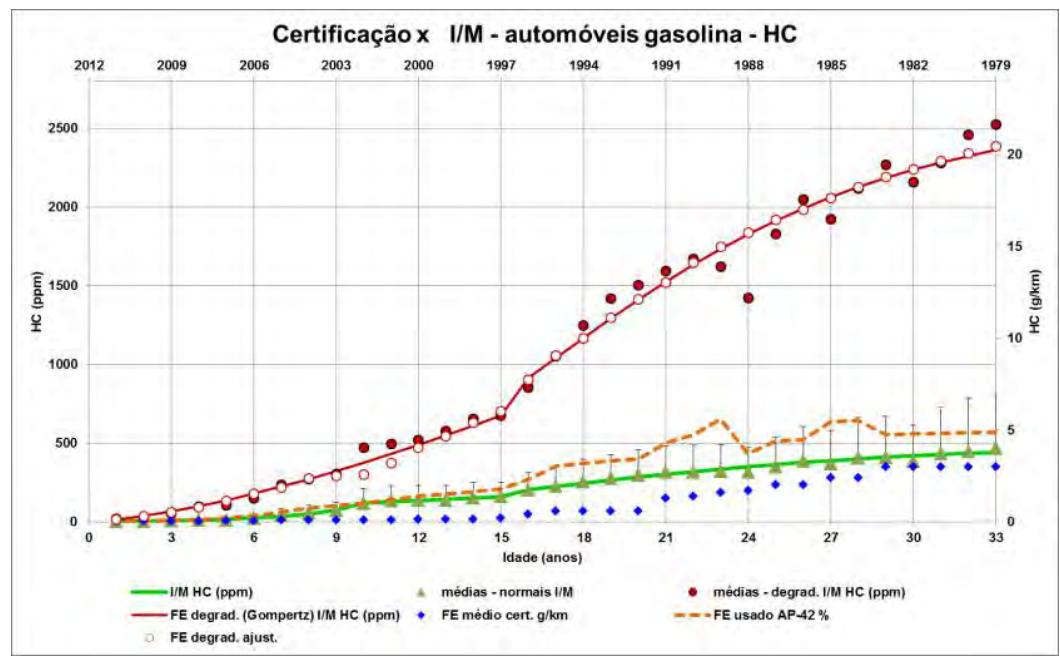

Figura 17 - Ajuste da curva dos fatores de emissão de HC dos veículos excessivamente deteriorados

No caso dos motociclos anteriores ao PROMOT, as curvas dos fatores de emissão determinadas pelos critérios anteriores são incompatíveis com níveis de consumo razoáveis. Por isso, foram reduzidas por um fator de ajuste adicional, constante para todos os anos de fabricação, de forma a aproximar os valores calculados da faixa aceitável de consumo, como indicado nos gráficos inferiores da figura 18.

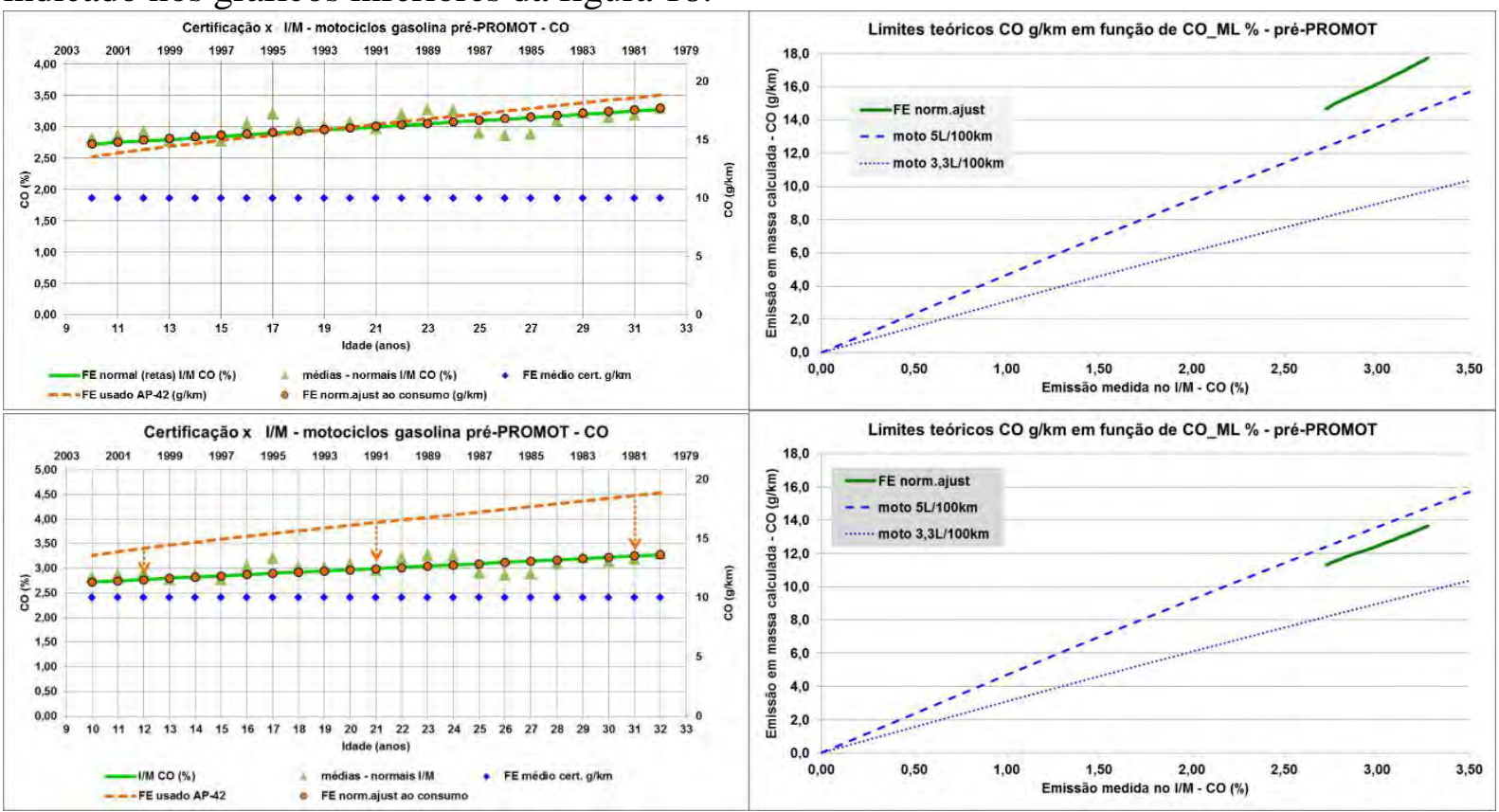

Figura 18 - Exemplo em que o cálculo dos fatores de emissão em massa resultou em consumo excessivo de combustível e sua correção

No exemplo da figura 18 foi necessária uma redução de $30 \%$ em todos os fatores de emissão calculados de forma a compatibilizá-los com o consumo esperado (indicada pelas setas alaranjadas). 


\section{RESULTADOS OBTIDOS}

Este trabalho resultou em dois conjuntos de curvas de fatores de emissão no ano base, um para veículos bem mantidos e outro para os altamente degradados, específicas para cada poluente, por tipo de veículo e combustível, representando uma grande quantidade de dados que não poderia ser publicada neste trabalho por falta de espaço. A figura 19 resume graficamente os resultados de $\mathrm{CO}$ e $\mathrm{HC}$ para automóveis a gasolina, separadamente para veículos bem mantidos, mal mantidos e média ponderada da frota, comparando-os aos valores de certificação.

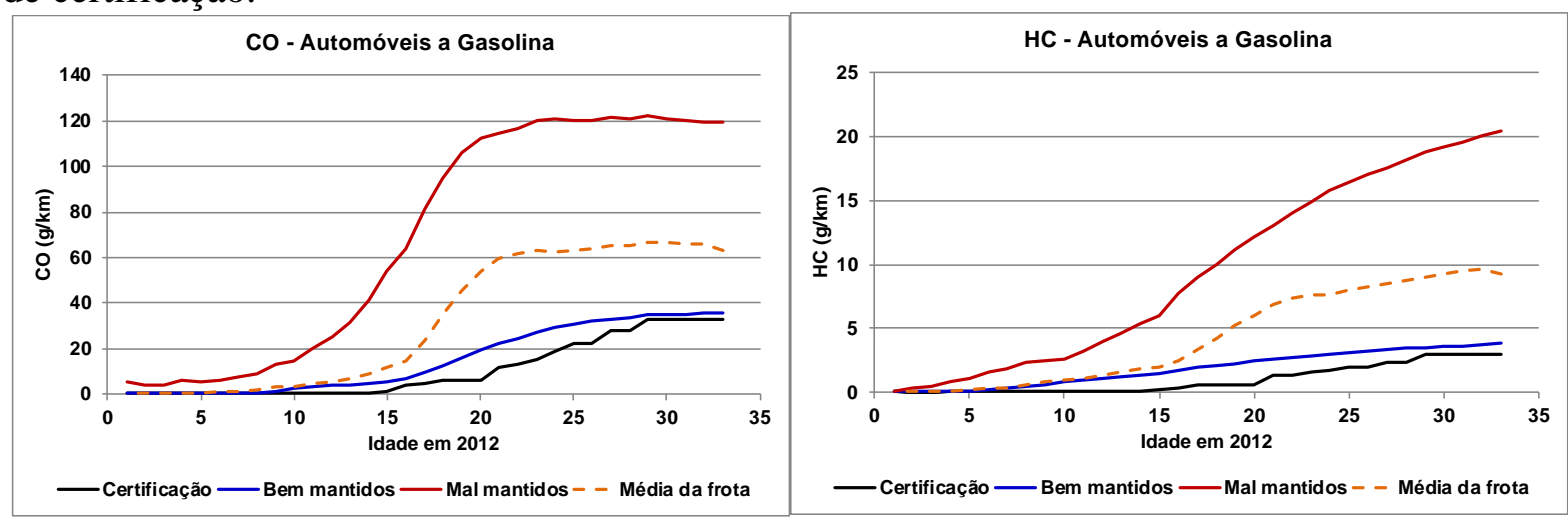

Figura 19 - Fatores de emissão de CO e HC para automóveis a gasolina

Para os veículos do ciclo Otto, entretanto, apenas os fatores de deterioração de $\mathrm{CO}$ e $\mathrm{HC}$ puderam ser obtidos por este método, pois são os únicos poluentes medidos no Programa I/MSP para este tipo de veículo, conforme a Resolução CONAMA 418/2009. Uma alternativa encontrada para obter os fatores de deterioração dos demais poluentes, principalmente Óxidos de nitrogênio (NOx), foi a de buscá-los no AP-42 norte-americano, balizando pelo tipo de tecnologia, pelos fatores de emissão de certificação e pelos fatores de deterioração de $\mathrm{CO}$ e HC previamente obtidos. O mesmo vale para os veículos do ciclo Diesel, cuja inspeção fornece apenas dados de opacidade (conversíveis para MP), sendo necessário utilizar os fatores norte-americanos para $\mathrm{CO}, \mathrm{HC}$ e NOx.

Futuramente estas estimativas poderão ser refinadas com base em dados de sensoriamento remoto e outros métodos de $\mathrm{I} / \mathrm{M}$ que abarquem os quatro poluentes, utilizando a mesma metodologia aqui proposta para obtenção dos fatores de deterioração.

Em relação a aldeídos e outros compostos orgânicos, a alternativa atual é utilizar os mesmos fatores de deterioração de $\mathrm{HC}$ e aplicá-los sobre as emissões certificadas ou sobre a especiação do HC de certificação nos casos em que o poluente não conste da certificação, como é o caso dos aldeídos de veículos do ciclo Diesel, por exemplo.

Este trabalho demonstra que os fatores de degradação reais da frota circulante são significativamente mais elevados do que os determinados pelo teste AMA, mesmo considerando somente os veículos em bom estado de manutenção (aprovados no I/M), mas ainda consistentes com os determinados nos EUA para veículos de mesmo padrão tecnológico. Por esse motivo é recomendável que os fatores de deterioração prefixados pelo PROCONVE, como alternativa às determinações pelo procedimento AMA, sejam os determinados na condição real de manutenção e utilização, para induzir os fabricantes a tomar medidas que assegurem efetivamente a durabilidade das emissões ao longo da vida útil do veículo e demonstrá-las através da realização dos ensaios AMA, ressalvando-se que estes resultados devem ser confirmados por monitoramento em campo e pelos Programas I/M nos anos seguintes. A tabela 2 mostra um resumo dos fatores obtidos para a última fase do 
PROCONVE das principais categorias de veículo, em termos de porcentagem de acréscimo do valor de certificação para as quilometragens indicadas. Considera-se que a última fase vigente deve ser a melhor fonte de informações sobre deterioração para a previsão da fase seguinte.

Tabela 2 - Fatores de Deterioração das emissões

\begin{tabular}{|l|c|c|c|}
\hline Ciclo do motor & HC & CO & MP \\
\hline Otto leves $-160 \mathrm{kkm}$ & $40 \%$ & $70 \%$ & \\
\hline Diesel leves $-160 \mathrm{kkm}$ & & & $40 \%$ \\
\hline Diesel pesados $(<30 \mathrm{t})-300 \mathrm{kkm}$ & & & $76 \%$ \\
\hline Diesel pesados $(\geq 30 \mathrm{t})-300 \mathrm{kkm}$ & & & $43 \%$ \\
\hline Motociclos $-80 \mathrm{kkm}$ & $560 \%$ & $260 \%$ & \\
\hline
\end{tabular}

A metodologia apresentada se aplica também para a análise das estatísticas levantadas a partir de monitoramento em condições reais, medidos por sensoriamento remoto ou a partir dos resultados de Programas I/M, possibilitando melhor conhecimento da frota circulante e adoção de eventuais ações corretivas sobre os modelos cujos resultados dos testes AMA não sejam confirmados na prática.

Este trabalho também permitiu a determinação das proporções das frotas que foram reprovadas ou rejeitadas na primeira inspeção dos veículos no Programa I/M-SP, além dos fatores de emissão calculados, as quais podem ser utilizadas para determinar os fatores de emissão médios da frota, através da composição entre veículos normais e excessivamente deteriorados. Com as diferenças encontradas nos fatores de degradação da frota circulante e as proporções de veículos normais e os que apresentam mau estado de conservação, se verifica que a revisão dos inventários atuais de emissões elaborados com base nos fatores AMA é mandatória pois todos estão subestimados.

\section{CONCLUSÕES E RECOMENDAÇÕES PARA PRÓXIMAS ETAPAS}

Os fatores de emissão determinados por este trabalho são bastante realistas e resultaram coerentes com as curvas das emissões obtidas do Programa I/M-SP. Tais resultados se prestam bem para a elaboração de estimativas de emissão das frotas de veículos no ano de referência do estudo, isto é 2012, representando avanço considerável para a elaboração de inventários de emissão de veículos automotores.

Porém, estes Fatores de Emissão, ao serem convertidos em Fatores de Deterioração em função da idade dos veículos ou da quilometragem, não resultaram em FD's iguais para cada fase do PROCONVE pois, de um ano para outro, variam simultaneamente a quilometragem (idade) e os modelos (tecnologias) de veículos.

Para a determinação efetiva de fatores de deterioração em função exclusiva da idade ou da quilometragem será necessário repetir os mesmos levantamentos estatísticos para diversos anos-exercício e processá-los comparando os mesmos veículos em anos subsequentes, onde a quilometragem se comportaria como variável independente produzindo funções de deterioração aplicáveis aos anos seguintes a 2012. 


\section{REFERÊNCIAS BIBLIOGRÁFICAS}

${ }^{1}$ Branco, G. M.; Branco, F. C. e Szwarc, A. (2012) - Fatores de Emissão de Veículos em Condições Reais de Utilização. Relatório CONTROLAR Nº 2012/09. Relatório interno.

${ }^{2}$ Branco, G.M.; Croce, W.; Branco, F.C.; Szwarc, A.; Napoleone, J. M. (2012) - Critérios De Avaliação Da Eficácia do Programa de Inspeção Veicular, apresentado no XX SIMEA Simpósio Internacional de Engenharia Automotiva

${ }^{3}$ US EPA - Compilation of Air Pollution Emission Factors - 1995

${ }^{4}$ Dodd, A.G. and Holubecki, Z. - DX250 Smokemeter Program UK MOT 2002 - Conversion chart for k, HSU, FSN and $\mathrm{mg} / \mathrm{m}^{3}$, extracted from MIRA Report No. 1965/10, Nuneaton Warwickshire, UK - 1965.

${ }^{5}$ Bruni, A.C. et al. (2013) - Curvas de Intensidade de Uso por Tipo de Veículo Automotor da Frota da Cidade de São Paulo - CETESB série relatórios.

${ }^{6}$ US EPA Emission Durability Procedures for new LDV, LDT and HDV - Final Rule Federal Register Vol 71, n¹0 Tuesday, January 17, 2006

${ }^{7}$ Brandão, M.; Branco, G.M.; Branco F.C.; Szwarc, A.; Mello Fo , L.V.F. (2012) - Critérios para a Inspeção de Veículos do Ciclo Otto Movidos a GNV - XX SIMEA. 